Article

\title{
Fluorescent Polyion Complex for the Detection of Sodium Dodecylbenzenesulfonate
}

\author{
Shuai Liu ${ }^{1}$, Cun $\mathrm{Hu}^{1}{ }^{1}$, , Jianbin Huang ${ }^{2}$ and Yun Yan ${ }^{2, *}$ \\ 1 College of Chemistry and Chemical Engineering, Southwest Petroleum University, Chengdu 610500, China; \\ shuailiu@swpu.edu.cn (S.L.); hucun402@stu.swpu.edu.cn (C.H.) \\ 2 Beijing National Laboratory for Molecular Sciences, Institution College of Chemistry and Molecular \\ Engineering, Peking University, Beijing 100871, China; jbhuang@pku.edu.cn \\ * Correspondence: yunyan@pku.edu.cn; Tel.: +86-010-6276-5058
}

Received: 4 May 2018; Accepted: 8 June 2018; Published: 12 June 2018

\begin{abstract}
Polyion complexes have been known about for decades, with their applications mainly restricted to drug and gene delivery. In this study, we show that by the introduction of fluorescent charged molecules into a polyion complex, it can be used as a specific detection system for surfactants. The fluorescence of 8-hydroxy-1,3,6-pyrenetrisulfonic acid trisodium salt (HPTS) is quenched in the ionic complex, while it can be recovered with the addition of the surfactant sodium dodecylbenzenesulfonate (SDBS), due to the stronger interaction between SDBS and the polyelectrolyte. This leads to a drastic color change of the solution, and a recovery of the strong emission of HPTS. Specifically, the fluorescence is linearly proportional to the concentration of SDBS, thus it can be used for the qualitative detection of SDBS. Furthermore, the detection limit for SDBS can be up to the order of $10^{-10} \mathrm{M}$. We believe that competitive dissociation of the ionic complex can be used as a general approach for the construction of new functional materials.
\end{abstract}

Keywords: polyion complexes; surfactant detection; competitive dissociation; HPTS; SDBS

\section{Introduction}

Polyion complexes have attracted significant attention because of their facile formation [1-4] and great potential in biomedical applications [5,6], especially in drug delivery and gene transfection [7-10]. Diblock polyelectrolyte poly( $N$-methyl-2-vinylpyridinium iodide)-b-poly (ethylene oxide) ( $\left.\mathrm{PMVP}_{41}-b-\mathrm{PEO}_{205}\right)$ has been widely employed to construct various polyion complexes with an oppositely charged component [11-13]. The polyion complexes can be made into micelles [14-16], vesicles [17-19], films [20,21], and even ultralong nanoladders [22]. So far, the practical application of various self-assemblies based on polyion complexes has mostly focused on drug and gene delivery, whereas other applications have not been sufficiently explored. This is mainly restricted by the fact that most of the self-assemblies are built with simple polyelectrolytes, which lack functional groups. In a previous work, the polyion complex built with $\mathrm{PMVP}_{41}-b-\mathrm{PEO}_{205}$ and 5,10,15,20-tetrakis (4-sulfonatophenyl) porphyrin (TPPS) was used to suppress the generation of singlet oxygen by TPPS [23]. Obviously, the employment of small charged functional molecules can endow polyion complex self-assemblies with rich functions. Since ionic complexation may change the physical properties of the encaged small molecules, we expect that sufficient competitive electrostatic interaction will allow dissociation of the ionic complex, thus triggering signal change. Clearly, this forms the basis for chemical sensing or detection. However, until now, insufficient attention has been paid to the use of polyion complexes in this manner, which is in great contrast to the increasing requirements for the precise and specific detection of chemicals in many fields. 
It is well known that surfactants play an increasingly vital role in daily life, since they are extensively applied in domestic detergents, and in industrial and agricultural fields as emulsifiers, lubricants, thickening and foaming agents etc. [24,25]. As a result, surfactants have become one of the major pollutants in the natural environment. Thus, it is becoming important to be able to facilely detect trace amounts of surfactants in water. So far, many well known analytical methods, including high-performance liquid chromatography [26,27], GC/MS [28,29], potentiometry [30], capillary electrophoresis [31], flow injection analysis [32], and optical detection [33-35], have been developed for the detection of surfactants. However, all of these methods have limitations to some extent, such as time-consuming and tedious procedures, the requirement of expensive equipment, the use of toxic solvents, unsatisfactory selectivity, and sensitivity. In addition, not all surfactants do serious harm to the environment, as surfactants with aliphatic chains can be degraded by microorganisms within 1 week [36]. Only those with aromatic rings, such as sodium dodecylbenzenesulfonate (SDBS), which is the major component in detergent powders, produce notorious environmental problems. However, so far, an effective method for the specific detection of SDBS is still missing. Although high detection limits for SDBS have been reported with some designed small fluorescent molecules, or using conjugated polymers as probes [37-41], the detection of SDBS may be interfered with by the sodium salts of fatty acids. For this reason, concerns about the status of water are produced. Therefore, it is highly desirable to distinguish SDBS from other surfactants with aliphatic chains in a simple, selective, and sensitive way.

In this work, we report that using the principle of competitive ionic interaction in a fluorescent polyion complex formed with a polymer containing the aromatic ring of pyridium, the facile visual specific detection of the surfactant sodium dodecylbenzenesulfonate (SDBS) is possible. The chemistry behind this is that the benzene ring in SDBS may specifically undergo aromatic interaction $(\pi-\pi$ stacking) with the pyridium group, among other aliphatic surfactants. As a result, the release of the fluorescent species from the original ionic complex may be accompanied by the spectral change. To verify this hypothesis, we first built the ionic complex with $\mathrm{PMVP}_{41}-b-\mathrm{PEO}_{205}$ and the commercially available fluorescent molecule 8-hydroxy-1,3,6-pyrenetrisulfonic acid trisodium salt (HPTS). $\mathrm{PMVP}_{41}-b-\mathrm{PEO}_{205}$ is a cationic block copolymer containing pyridium groups, whereas HPTS carries three negative charges on a large aromatic plane, which allows it to efficiently form an ionic complex with the cationic block polyelectrolyte $\mathrm{PMVP}_{41}-b-\mathrm{PEO}_{205}$ through electrostatic and aromatic stacking interactions. Before complexation, HPTS displays significant fluorescence with a quantum yield $(\Phi)$ of 0.82 in water [42]. However, the emission of HPTS is quenched drastically upon the formation of an ionic complex with $\mathrm{PMVP}_{41}-b-\mathrm{PEO}_{205}$. We assume that the fluorescence of HPTS can be recovered by the introduction of SDBS, as opposed to other aliphatic surfactants, as SDBS offers additional aromatic interactions with the pyridinium group of the $\mathrm{PMVP}_{41}-b-\mathrm{PEO}_{205}$ when compared to other aliphatic surfactants. To this end, different anionic surfactants were added to the system, as they can interact with the cationic $\mathrm{PMVP}_{41}-b-\mathrm{PEO}_{205}$ through the synergistic effect of electrostatic interaction and hydrophobic interaction, thus disassembling the $\mathrm{PMVP}_{41}-b-\mathrm{PEO}_{205} / \mathrm{HPTS}$ complex. Indeed, the fluorescence of HPTS recovers with the addition of anionic surfactants. Remarkably, the extent of the fluorescence recovery strongly depends on the structure of the added anionic surfactant, and displays specific recovery behavior toward SDBS (Scheme 1). Meanwhile, the optical absorption also displays drastic changes upon the addition of SDBS. Therefore, we established a new colorimetric and fluorescent dual responsive system toward the specific detection of SDBS in water. To the best of our knowledge, this is the first time that the polyelectrolyte $\mathrm{PMVP}_{41}-b-\mathrm{PEO}_{205}$ has been used for the discrimination of a specific anionic surfactant. 


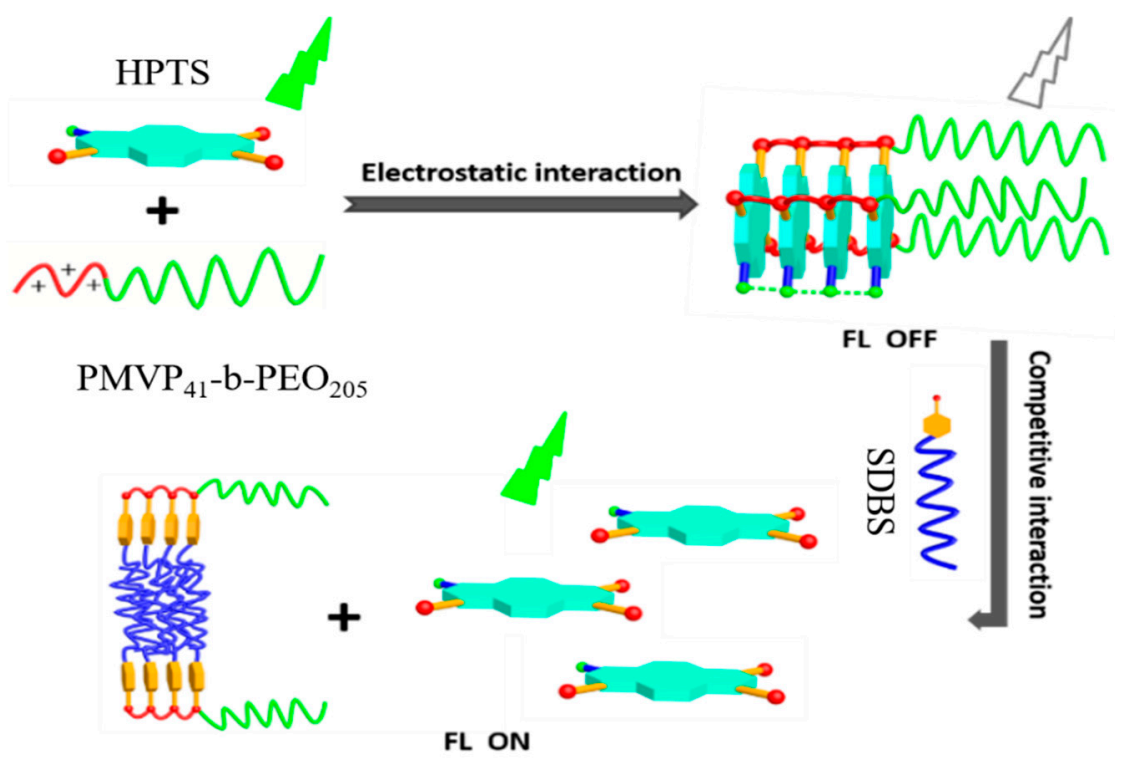

Scheme 1. Illustration of the self-assembly of the HPTS/PMVP $41-b-\mathrm{PEO}_{205}$ complex and disassembly of the ionic self-assembled polyion complex in the presence of sodium dodecylbenzenesulfonate (SDBS).

\section{Materials and Methods}

\subsection{Materials and Measurements}

Diblock polyelectrolyte poly( $N$-methyl-2-vinylpyridinium iodide)- $b$-poly(ethylene oxide) $\left(\mathrm{PMVP}_{41}-b-\mathrm{PEO}_{205}, M_{\mathrm{W}}=19 \mathrm{~K}, \mathrm{PDI}=1.05\right.$, about $90 \%$ quaternized $)$ used in this work was prepared according to previously reported procedures [43]. 8-hydroxy-1,3,6-pyrenetrisulfonic acid trisodium salt (HPTS) was purchased from Sigma-Aldrich (Shanghai, China). The structures of HPTS and $\mathrm{PMVP}_{41}-b-\mathrm{PEO}_{205}$ are given in Scheme 2. All other chemicals were purchased from Beijing Chem. Reagents Co. (Beijing, China) and were used as received. Ultrapure water was used throughout the work. The other reagents were of A. R. grade.

A UV-1800 SHIMADZU spectrophotometer (Hitachi. Ltd., Tokyo, Japan) in the range of 200-700 $\mathrm{nm}$ was used to measure the absorption of solution samples.

A Hitachi F7000 Fluorescence Spectrometer (Hitachi. Ltd., Tokyo, Japan) was used to measure the fluorescence emission of solution samples. The excitation wavelength was set at $405 \mathrm{~nm}$, which is the characteristic absorption peak of HPTS given in product information.

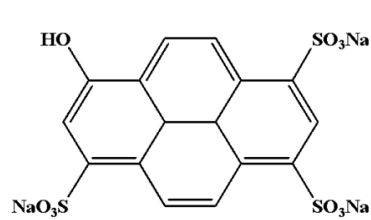

HPTS

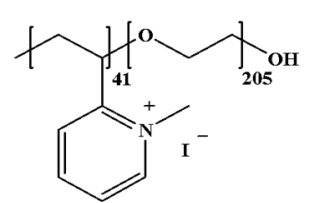

PMVP $_{41}-$ b-PEO 205

Scheme 2. The molecular structures of 8-hydroxy-1,3,6-pyrenetrisulfonic acid trisodium salt (HPTS) and poly( $N$-methyl-2-vinylpyridinium iodide)- $b$-poly (ethylene oxide) $\left(\mathrm{PMVP}_{41}-b-\mathrm{PEO}_{205}\right)$.

\subsection{Sample Preparation}

The $\mathrm{PMVP}_{41}-b-\mathrm{PEO}_{205} / \mathrm{HPTS}$ complex was prepared by adding $\mathrm{PMVP}_{41}-b-\mathrm{PEO}_{205}$ stock solution into a dilute aqueous solution of HPTS with the given concentration. Here, the concentration of $\mathrm{PMVP}_{41}-b-\mathrm{PEO}_{205}$ is the concentration of positive charges. The ratio of HPTS to $\mathrm{PMVP}_{41}-b-\mathrm{PEO}_{205}$ in 
the complex was kept at 1:8 for surfactant detection, since higher ratios lead to the waste of agents. All experiments were performed at room temperature ( $298 \mathrm{~K})$ unless otherwise specified.

\section{Results and Discussion}

\subsection{The Formation of Polyion Complex with $P M V P_{41}-P E O_{205}$ and Fluorescent Molecule HPTS}

The cationic diblock polyelectrolyte poly( $N$-methyl-2-vinylpyridinium iodide)- $b$-poly(ethylene oxide) ( $\left.\mathrm{PMVP}_{41}-b-\mathrm{PEO}_{205}\right)$ is chosen to construct a sensing system for surfactants, since it can easily form ionic self-assemblies with oppositely charged compounds. In this study, the negatively charged fluorescent molecule HPTS is employed to form an ionic complex with $\mathrm{PMVP}_{41}-b-\mathrm{PEO}_{205}$. Figure S1a shows that the absorption intensity increases with the increase in concentration of HPTS. The maximum absorption peak of HPTS is $403 \mathrm{~nm}$. At the range of $0.001 \sim 0.1 \mathrm{mM}$, the intensity of the maximum absorption peak of HPTS increases in a linear fashion, as shown in Figure S1b, in line with the Lambert-Beer Law. Therefore, the HPTS exists as a monomer when the concentration is $0.01 \mathrm{mM}$. Figure 1 shows the absorption spectra of HPTS $(0.01 \mathrm{mM})$ in aqueous solutions containing different concentrations of $\mathrm{PMVP}_{41}-b-\mathrm{PEO}_{205}$. HPTS on its own exhibits a characteristic absorption maximum at $403 \mathrm{~nm}$. By increasing the concentration of $\mathrm{PMVP}_{41}-b-\mathrm{PEO}_{205}$, the absorption intensity at $403 \mathrm{~nm}$ gradually decreases, while the new absorption at longer wavelengths increases, and finally forms a major peak at $464 \mathrm{~nm}$. In line with the occurrence of longer wave absorption, the solution displays a distinct color change from green to yellow (Figure 1. inset). Considering that the absorbance of $\mathrm{PMVP}_{41}-b-\mathrm{PEO}_{205}$ only occurs at $264 \mathrm{~nm}$ (Figure S2), the decrease of the absorbance at $403 \mathrm{~nm}$ and the appearance of a new band at $464 \mathrm{~nm}$ are ascribed to the formation of the polyion complex [44,45].

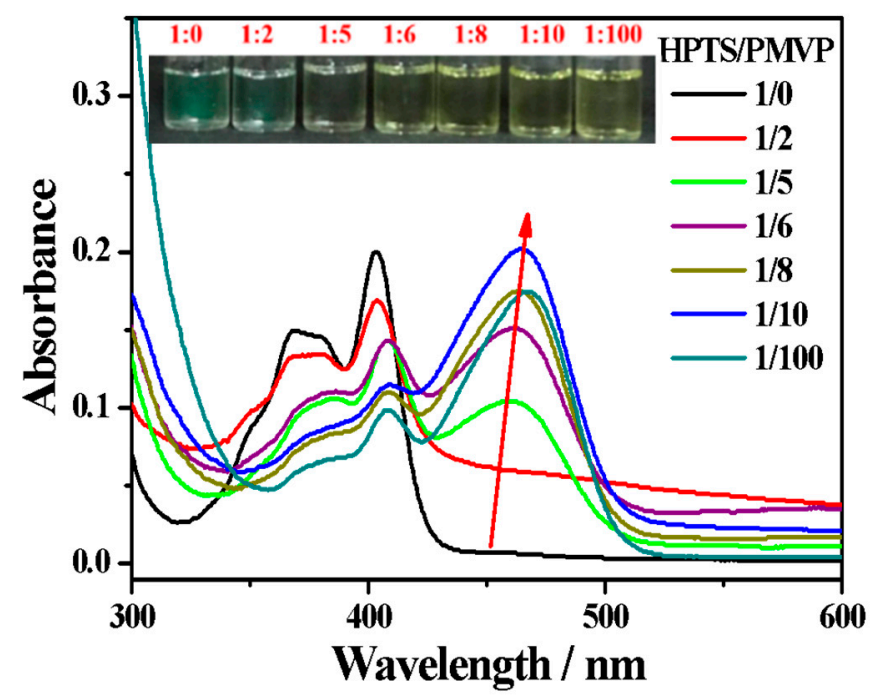

Figure 1. UV-Vis absorption spectra of 8-hydroxy-1,3,6-pyrenetrisulfonic acid trisodium salt (HPTS) $(0.01 \mathrm{mM})$ in water at different charge ratios of HPTS: PMVP. Inset shows that the complex color with different charge ratios of HPTS: PMVP changes under daylight. PMVP is the abbreviation of $\mathrm{PMVP}_{41}$-b- $\mathrm{PEO}_{205}$ (poly(N-methyl-2-vinylpyridinium iodide)-b-poly(ethylene oxide)).

The fluorescence spectra of HPTS before and after the addition of various amounts of $\mathrm{PMVP}_{41}-b-\mathrm{PEO}_{205}$ are shown in Figure 2. Clearly, the emission maxima (512 nm) of the HPTS are gradually weakened by increasing the concentration of $\mathrm{PMVP}_{41}-b-\mathrm{PEO}_{205}$ in the solutions. The emission is completely quenched as the charge ratio of HPTS: $\mathrm{PMVP}_{41}-b-\mathrm{PEO}_{205}$ reaches 1:6. The photographs of these solutions under UV light $(365 \mathrm{~nm})$ reveal that the fluorescence quenching can be easily observed by the naked eye. 


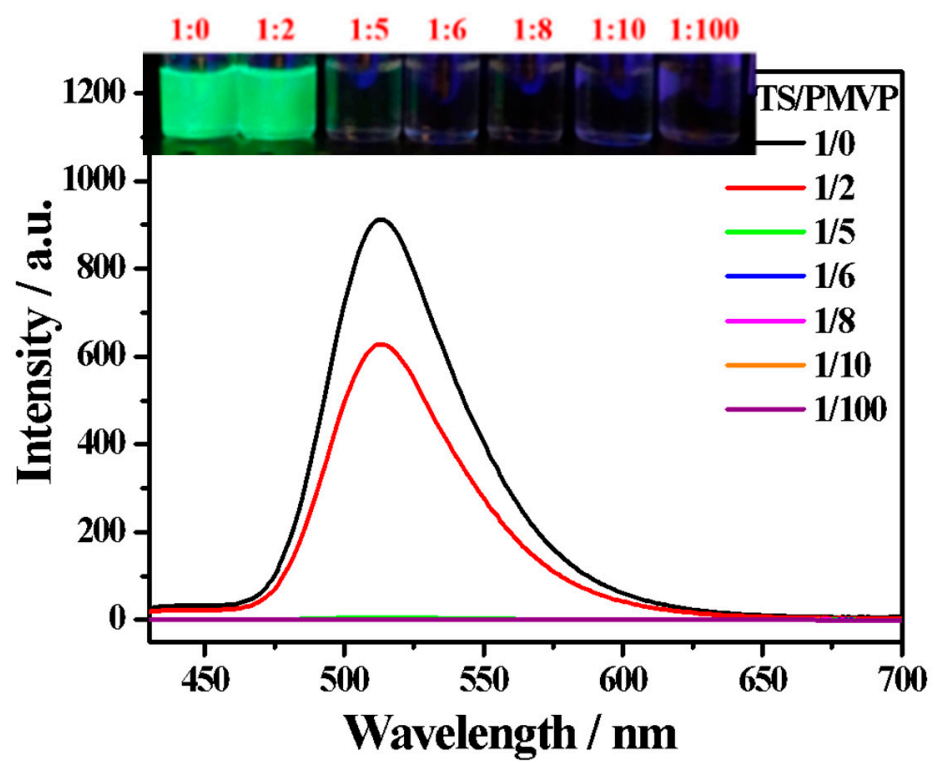

Figure 2. Fluorescence spectra of HPTS $(0.01 \mathrm{mM})$ in water at different charge ratios of HPTS: PMVP. Excitation wavelength: $405 \mathrm{~nm}$. Inset shows that the complex emission color with different charge ratios of HPTS:PMVP changes under a UV (365 nm) lamp. PMVP is the abbreviation of $\mathrm{PMVP}_{41}-b-\mathrm{PEO}_{205}$.

\subsection{Detection of Anionic Surfactants Based on the Disassembly of the Ionic Self-Assembled Polyion Complex}

Because the formation of the $\mathrm{PMVP}_{41}-b-\mathrm{PEO}_{205} / \mathrm{HPTS}$ complex is driven by electrostatic interaction, the optical properties of the ionic self-assembled complex are sensitive to any competitive ionic molecules. This provides us with an opportunity to detect molecules of interest in the solution. Since ionic surfactants are known to form well-defined ionic complex micelles with block polyelectrolytes [46-48], in the following paragraphs, we explore the possibility of detecting anionic surfactants using the present HPTS/ $\mathrm{PMVP}_{41}-b-\mathrm{PEO}_{205}$ system.

To address the selectivity of the $\mathrm{PMVP}_{41}-b-\mathrm{PEO}_{205} / \mathrm{HPTS}$ complex toward anionic surfactants, various surfactants were added. Figure 3 shows the absorption and emission spectra of the $\mathrm{PMVP}_{41}-b-\mathrm{PEO}_{205} / \mathrm{HPTS}$ solution upon the addition of sodium dodecyl sulfonate (SDS), sodium dodecylbenzenesulfonate (SDBS), cetyltrimethylammonium bromide (CTAB), Triton X-100, tetradecyl dimethyl amine oxide $\left(\mathrm{C}_{14} \mathrm{DMAO}\right)$, tetradecyl dimethylammonium propane sulfonate (TDPS), and simple ions, including $\mathrm{K}^{+}, \mathrm{Na}^{+}$, and $\mathrm{Cl}^{-}$. Moreover, the absorption and emission spectra of the $\mathrm{PMVP}_{41}-b-\mathrm{PEO}_{205} / \mathrm{HPTS}$ solution upon the addition of the organic salts sodium salicylate (SS) and sodium benzoate (SB) are also measured, as shown in Figure S3a. Only anionic surfactants (SDS and SDBS) induce the distinct fluorescence recovery of HPTS at $512 \mathrm{~nm}$, whereas the cationic (CTAB), non-ionic ( $\left.\mathrm{C}_{14} \mathrm{DMAO}\right)$, and zwitterionic (TDPS) surfactants and simple ions cannot recover the emission (Figure 3b). Similarly, the organic salts sodium salicylate (SS) and sodium benzoate (SB) are also unable to recover the emission (Figure S3b).

Meanwhile, the optical appearance varies with the addition of different anionic surfactants. For instance, the system with SDBS is light green, while the system with SDS is pale yellow (Figure 4). In line with this, both the UV-Vis absorption and the fluorescence emission show significant spectral difference. The absorbance of HPTS at $403 \mathrm{~nm}$ increases, while the HPTS absorbance of the complex at $464 \mathrm{~nm}$ decreases upon the addition of SDBS, whereas the absorption triggered by SDS is drastically reduced. In addition, the emission with SDBS is an intense green, whereas the emission with SDS is light green. These drastic spectral differences allow us to distinguish between the anionic surfactants SDBS and SDS. Usually, it is hard to differentiate between anionic surfactants in an ionic complex, since they commonly display similar electrostatic interaction with polyions. It is possible that the benzene group in SDBS have interacted with the pyridine group in the $\mathrm{PMVP}_{41}$ block. Obviously, 
this specific interaction is much stronger than the nonspecific hydrophobic interaction that occurred between SDS and the PMVP $_{41}$ block.
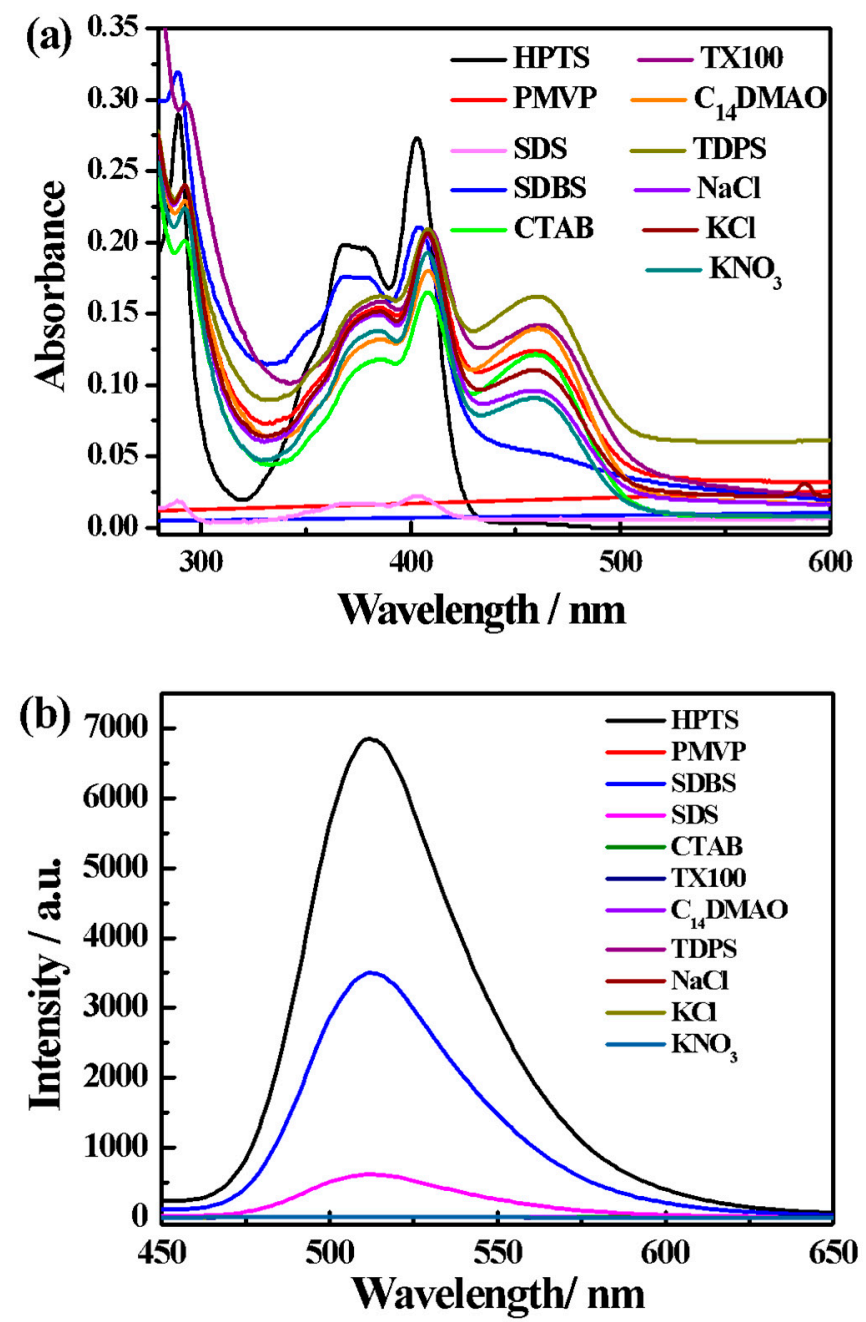

Figure 3. Absorption (a) and emission (b) spectra of the HPTS/PMVP $41-b-\mathrm{PEO}_{205}$ complex in water in the presence of various analytes. $[\mathrm{HPTS}]=0.05 \mathrm{mM} ;[\mathrm{PMVP}]=0.4 \mathrm{mM} ;[\mathrm{SDS}]=[\mathrm{SDBS}]=[\mathrm{CTAB}]=$ $[$ Triton $\mathrm{X}-100]=\left[\mathrm{C}_{14} \mathrm{DMAO}\right]=[\mathrm{TDPS}]=0.2 \mathrm{mM} ;[\mathrm{KCl}]=[\mathrm{NaCl}]=\left[\mathrm{KNO}_{3}\right]=0.5 \mathrm{mM}$. PMVP is the abbreviation of $\mathrm{PMVP}_{41}-b-\mathrm{PEO}_{205}$.

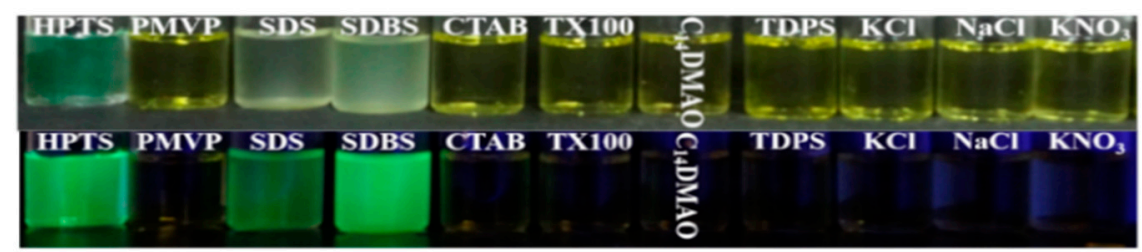

Figure 4. Changes in the color of HPTS/PMVP $41-b-\mathrm{PEO}_{205}$ complex in water in the presence of various analytes. $[\mathrm{HPTS}]=0.05 \mathrm{mM}$; $[\mathrm{PMVP}-\mathrm{PEO}]=0.4 \mathrm{mM}$; $[\mathrm{SDS}]=[\mathrm{SDBS}]=[\mathrm{CTAB}]=[$ Triton X-100] $=$ $\left[\mathrm{C}_{14} \mathrm{DMAO}\right]=[\mathrm{TDPS}]=0.2 \mathrm{mM} ;[\mathrm{KCl}]=[\mathrm{NaCl}]=\left[\mathrm{KNO}_{3}\right]=0.5 \mathrm{mM}$. PMVP is the abbreviation of $\mathrm{PMVP}_{41}-b-\mathrm{PEO}_{205}$ 


\subsection{Distinction and Quantitative Detection of Sodium Dodecylbenzenesulfonate}

To further confirm the specific detection of SDBS using the HPTS/PMVP $41-b-\mathrm{PEO}_{205}$ complex, different anionic surfactants were added into the HPTS $/ \mathrm{PMVP}_{41}-b-\mathrm{PEO}_{205}$ solution. Figure 5 a reveals that the characteristic absorption peak of HPTS at $403 \mathrm{~nm}$ can only be significantly recovered by the addition of SDBS. In contrast, this peak remains very low and broad as other surfactants are added. Accordingly, the emission spectra in Figure 5b manifest that only SDBS is able to induce the distinct fluorescence recovery of HPTS at $512 \mathrm{~nm}$. Other anionic surfactants, such as sodium dichloroisocyanurate (SDC), SDS, and sodium lauryl sulfate (SLS), only trigger weak fluorescence recovery. Obviously, the HPTS/PMVP ${ }_{41}-b-\mathrm{PEO}_{205}$ ionic complex can specifically detect SDBS, mainly due to the strong affinity of sulfonate for the quaternary ammonium group $[49,50]$.
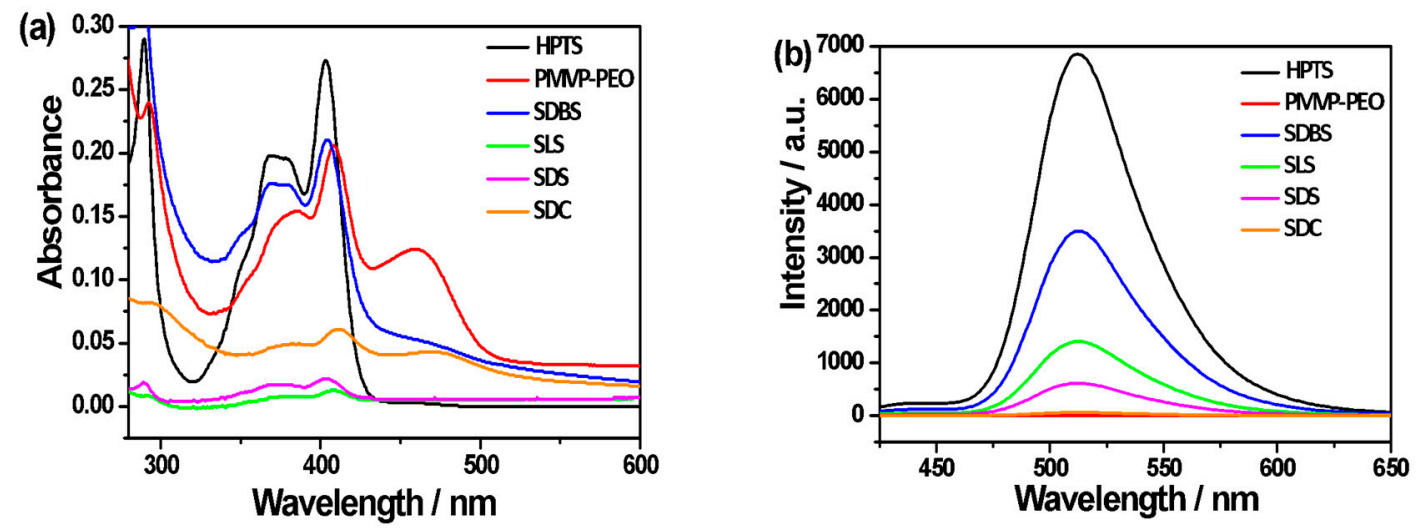

Figure 5. Absorption (a) and emission (b) spectra of the HPTS/PMVP $41-b-\mathrm{PEO}_{205}$ complex in water in the presence of different anionic surfactants. [PMVP-PEO] $=0.4 \mathrm{mM}$; [HPTS] $=0.05 \mathrm{mM}$; $[\mathrm{SDBS}]=[\mathrm{SLS}]=[\mathrm{SDS}]=[\mathrm{SDC}]=0.2 \mathrm{mM}$. PMVP-PEO is the abbreviation of $\mathrm{PMVP}_{41}-b-\mathrm{PEO}_{205}$.

Considering the high quantum yield of HPTS, the establishment of a qualitative fluorometric analysis is anticipated by monitoring the emission of HPTS. Figure 6 displays the emission spectra of the PMVP $41-b-\mathrm{PEO}_{205} / \mathrm{HPTS}$ complex in aqueous solution in the presence of different amounts of SDBS. Without the presence of SDBS, the emission of HPTS is severely quenched. However, the emission intensity is gradually enhanced by increasing the concentration of SDBS. Notably, a good linear relationship exists between the emission intensity at $512 \mathrm{~nm}$ and the concentration of SDBS from 5-100 nM ( $\mathrm{R}=0.9903)$, with good reproducibility. This implies that the $\mathrm{PMVP}_{41}-b-\mathrm{PEO}_{205} / \mathrm{HPTS}$ complex is potentially useful for the quantitative determination of SDBS concentrations based on a fluorescence turn-on response of HPTS, and the detection limit can be up to the order of $10^{-9} \mathrm{M}$. From the slope of the fitting line of the data in the linear response range $(k)$ and the deviation of fluorescent measurements $(\sigma)$ [51], the detection limit of the fluorescent polyion complex towards SDBS $(3 \sigma / k)$ was calculated to be $0.1 \mathrm{nM}$. This high sensitivity toward SDBS is amazing; we attribute it to the additional aromatic interaction between the benzene ring in SDBS and the pyridium group of PMVP. This additional aromatic interaction also facilitates the practical application of the HTPS $/ \mathrm{PMVP}_{41}-b-\mathrm{PEO}_{205}$ complex in the detection of SDBS in natural water. In Figure $6 c$, we show the experimental results of the detection effect in a model system of natural water containing different surfactants, including SDS, SL, and SDBS. We found that the fluorescence of HPTS is still observed, as the content of SDS and SL is twice as high as that of SDBS, confirming the practical possibilities. 

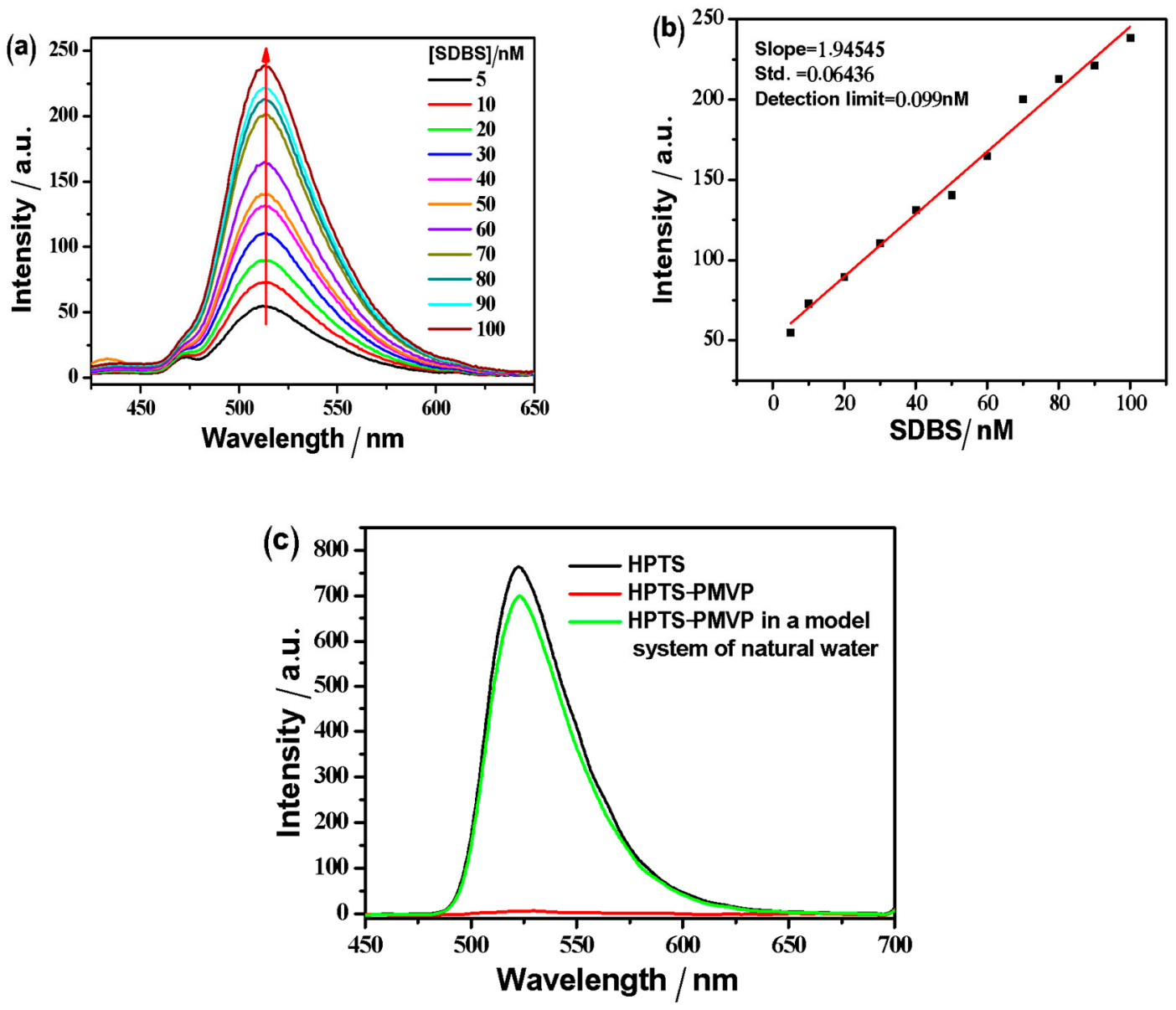

Figure 6. (a) Emission spectra of the HPTS/PMVP $41-b-\mathrm{PEO}_{205}$ complex in water in the presence of increasing amounts of SDBS; (b) The relationship between the emission intensity and the concentration of SDBS from 5 to $100 \mathrm{nM}$. R = 0.9903; (c) Emission spectra of the HPTS, HPTS/PMVP $41-b-\mathrm{PEO}_{205}$ complex and polyion complex in a model system of natural water which contains different surfactants, including SDS, SL, SDBS and simple organic ions. [SDBS] = $100 \mathrm{nM}$; [SDS] = [SLS] $=200 \mathrm{nM} ;[\mathrm{KCl}]=[\mathrm{NaCl}]=\left[\mathrm{KNO}_{3}\right]=0.2 \mathrm{mM}$. PMVP is the abbreviation of $\mathrm{PMVP}_{41}-b-\mathrm{PEO}_{205}$. $\left[\mathrm{PMVP}_{41}-b-\mathrm{PEO}_{205}\right]=0.6 \mu \mathrm{M}$; [HPTS $]=0.1 \mu \mathrm{M}$. Excitation wavelength: $405 \mathrm{~nm}$.

\section{Conclusions}

In conclusion, the fluorescent ionic complex formed by $\mathrm{PMVP}_{41}-b-\mathrm{PEO}_{205}$ and $\mathrm{HPTS}$ can be employed in the quantitative detection of SDBS in water. The fluorescence of HPTS is quenched in the ionic complex, but can be recovered by the addition of SDBS. The stronger interaction between SDBS and $\mathrm{PMVP}_{41}-b-\mathrm{PEO}_{205}$ is responsible for this fluorescence recovery, which leads to the release of HPTS from the ionic complex. The release of HPTS is also accompanied by a significant change in the solution's color, so that both the absorption and emission spectra can be applied to monitor the release of HPTS. We believe that the present work will not only develop a fast, simple, and convenient approach for sensing SDBS with the detection limit as low as $10^{-9} \mathrm{M}$, but will also provide an important clue to the construction of new functional materials based on polyion complexes.

Supplementary Materials: The following are available online at http:/ /www.mdpi.com/2073-4360/10/6/657/s1, Figure S1: (a) UV-Vis absorption spectra of HPTS solutions with a variety of concentrations. (b) The maximum absorption at $403 \mathrm{~nm}$ of HPTS solutions with a variety of concentrations; Figure S2: Absorption spectra of different concentrations of $\mathrm{PMVP}_{41}-b-\mathrm{PEO}_{205}$ in water; Figure S3: (a) Absorption and (b) Emission spectra of HPTS, HPTS/PMVP-PEO, HPTS/PMVP/SS, HPTS/PMVP/SB. 
Author Contributions: J.H., Y.Y., and S.L. conceived and designed the experiments; S.L. and C.H. performed the experiments; S.L. and C.H. analyzed the data; J.H. and Y.Y. contributed analysis tools; Y.Y. and S.L. wrote the paper.

Acknowledgments: This work was supported by the Natural Science Foundation of China (NSFC, Grant no. 21573011 and 21422302), Major State Basic Research Development Program of China (973 Program, 2013CB933800), Young Scholars Development Fund of SWPU (201599010093), Scientific Research Starting Project of SWPU (NO. 2017QHZ016) and National Natural Science Foundation of China (Project No: 21703177).

Conflicts of Interest: The authors declare no conflicts of interest.

\section{References}

1. Kabanov, A.V.; Bronich, T.K.; Kabanov, V.A.; Yu, K.; Eisenberg, A. Spontaneous formation of vesicles from complexes of block ionomers and surfactants. J. Am. Chem. Soc. 1998, 120, 9941-9942. [CrossRef]

2. Harada, A.; Kataoka, K. Chain length recognition: Core-shell supramolecular assembly from oppositely charged block copolymers. Science 1999, 283, 65-67. [CrossRef] [PubMed]

3. Nakai, K.; Ishihara, K.; Yusa, S.-I. Preparation of giant polyion complex vesicles (g-picsomes) with polyphosphobetaine shells composed of oppositely charged diblock copolymers. Chem. Lett. 2017, 46, 824-827. [CrossRef]

4. Kulig, D.; Zimoch-Korzycka, A.; Jarmoluk, A.; Marycz, K. Study on alginate-chitosan complex formed with different polymers ratio. Polymers 2016, 8, 17. [CrossRef]

5. Bae, Y.; Fukushima, S.; Harada, A.; Kataoka, K. Design of environment-sensitive supramolecular assemblies for intracellular drug delivery: Polymeric micelles that are responsive to intracellular ph change. Angew. Chem. Int. Ed. 2003, 42, 4640-4643. [CrossRef] [PubMed]

6. Harada, A.; Kataoka, K. Novel polyion complex micelles entrapping enzyme molecules in the core: Preparation of narrowly-distributed micelles from lysozyme and poly(ethylene glycol)-poly(aspartic acid) block copolymer in aqueous medium. Macromolecules 1998, 31, 288-294. [CrossRef]

7. Kataoka, K.; Harada, A.; Nagasaki, Y. Block copolymer micelles for drug delivery: Design, characterization and biological significance. Adv. Drug Deliv. Rev. 2012, 64, 37-48. [CrossRef]

8. Lee, Y.; Fukushima, S.; Bae, Y.; Hiki, S.; Ishii, T.; Kataoka, K. A protein nanocarrier from charge-conversion polymer in response to endosomal ph. J. Am. Chem. Soc. 2007, 129, 5362-5363. [CrossRef] [PubMed]

9. Chen, H.; Xiao, L.; Anraku, Y.; Mi, P.; Liu, X.; Cabral, H.; Inoue, A.; Nomoto, T.; Kishimura, A.; Nishiyama, N.; et al. Polyion complex vesicles for photoinduced intracellular delivery of amphiphilic photosensitizer. J. Am. Chem. Soc. 2014, 136, 157-163. [CrossRef] [PubMed]

10. Duro-Castano, A.; Conejos-Sanchez, I.; Vicent, M.J. Peptide-based polymer therapeutics. Polymers 2014, 6, 515-551. [CrossRef]

11. Baulin, V.A.; Trizac, E. Self-assembly of spherical interpolyelectrolyte complexes from oppositely charged polymers. Soft Matter 2012, 8, 6755-6766. [CrossRef]

12. Irigoyen, J.; Han, L.; Llarena, I.; Mao, Z.; Gao, C.; Moya, S.E. Responsive polyelectrolyte multilayers assembled at high ionic strength with an unusual collapse at low ionic strength. Macromol. Rapid Commun. 2012, 33, 1964-1969. [CrossRef] [PubMed]

13. Lazzara, T.D.; Lau, K.H.A.; Abou-Kandil, A.I.; Caminade, A.-M.; Majoral, J.-P.; Knoll, W. Polyelectrolyte layer-by-layer deposition in cylindrical nanopores. ACS Nano 2010, 4, 3909-3920. [CrossRef] [PubMed]

14. Chelushkin, P.S.; Lysenko, E.A.; Bronich, T.K.; Eisenberg, A.; Kabanov, V.A.; Kabanov, A.V. Polyion complex nanomaterials from block polyelectrolyte micelles and linear polyelectrolytes of opposite charge. 2. Dynamic properties. J. Phys. Chem. B 2008, 112, 7732-7738. [CrossRef] [PubMed]

15. Voets, I.K.; de Keizer, A.; Leermakers, F.A.M.; Debuigne, A.; Jerome, R.; Detrembleur, C.; Stuart, M.A.C. Electrostatic hierarchical co-assembly in aqueous solutions of two oppositely charged double hydrophilic diblock copolymers. Eur. Polym. J. 2009, 45, 2913-2925. [CrossRef]

16. Wu, Z.; Huang, J.B.; Yan, Y. Electrostatic polyion micelles with fluorescence and mri dual functions. Langmuir 2015, 31, 7926-7933. [CrossRef] [PubMed]

17. Anraku, Y.; Kishimura, A.; Yamasaki, Y.; Kataoka, K. Living unimodal growth of polyion complex vesicles via two-dimensional supramolecular polymerization. J. Am. Chem. Soc. 2013, 135, 1423-1429. [CrossRef] [PubMed] 
18. Nakai, K.; Ishihara, K.; Kappl, M.; Fujii, S.; Nakamura, Y.; Yusa, S. Polyion complex vesicles with solvated phosphobetaine shells formed from oppositely charged diblock copolymers. Polymers 2017, 9, 15. [CrossRef]

19. Taabache, S.; Bertin, A. Vesicles from amphiphilic dumbbells and janus dendrimers: Bioinspired self-assembled structures for biomedical applications. Polymers 2017, 9, 36. [CrossRef]

20. Shin, K.; Rafailovich, M.H.; Sokolov, J.; Chang, D.M.; Cox, J.K.; Lennox, R.B.; Eisenberg, A.; Gibaud, A.; Huang, J.; Hsu, S.L. Observation of surface ordering of alkyl side chains in polystyrene/polyelectrolytes diblock copolymer langmuir films. Langmuir 2001, 17, 4955-4961. [CrossRef]

21. Jha, P.K.; Desai, P.S.; Li, J.; Larson, R.G. Ph and salt effects on the associative phase separation of oppositely charged polyelectrolytes. Polymers 2014, 6, 1414-1436. [CrossRef]

22. Xu, L.M.; Jiang, L.X.; Drechsler, M.; Sun, Y.; Liu, Z.R.; Huang, J.B.; Tang, B.Z.; Li, Z.B.; Stuart, M.A.C.; Yan, Y. Self-assembly of ultralong polyion nanoladders facilitated by ionic recognition and molecular stiffness. J. Am. Chem. Soc. 2014, 136, 1942-1947. [CrossRef] [PubMed]

23. Zheng, R.Y.; Wu, Z.; Yan, Y.; Wang, J.D.; Huang, J.B. Suppressing singlet oxygen formation from 5,10,15,20-tetrakis(4-sulfonatophenyl) porphyrin using polyion complex micelles. RSC Adv. 2015, 5, 17253-17256. [CrossRef]

24. Chen, X.; Kang, S.; Kim, M.J.; Kim, J.; Kim, Y.S.; Kim, H.; Chi, B.; Kim, S.J.; Lee, J.Y.; Yoon, J. Thin-film formation of imidazolium-based conjugated polydiacetylenes and their application for sensing anionic surfactants. Angew. Chem. Int. Ed. 2010, 49, 1422-1425. [CrossRef] [PubMed]

25. Olkowska, E.; Polkowska, Z.; Namiesnik, J. Analytics of surfactants in the environment: Problems and challenges. Chem. Rev. 2011, 111, 5667-5700. [CrossRef] [PubMed]

26. Di, C.A.; Samperi, R.; Marcomini, A. Monitoring aromatic surfactants and their biodegradation intermediates in raw and treated sewages by solid-phase extraction and liquid chromatography. Environ. Sci. Technol. 1994, $28,850-858$.

27. Corcia, A.D.; Marchetti, M.; Samperi, R.; Marcomini, A. Liquid chromatographic determination of linear alkylbenzenesulfonates in aqueous environmental samples. Anal. Chem. 1991, 63, 1179-1182. [CrossRef] [PubMed]

28. Moldovan, Z.; Avram, V.; Marincas, O.; Petrov, P.; Ternes, T. The determination of the linear alkylbenzene sulfonate isomers in water samples by gas-chromatography/mass spectrometry. J. Chromatogr. A 2011, 1218, 343-349. [CrossRef] [PubMed]

29. Ding, W.H.; Tsai, P.C. Determination of alkyltrimethylammonium chlorides in river water by gas chromatography/ion trap mass spectrometry with electron impact and chemical ionization. Anal. Chem. 2003, 75, 1792-1797. [CrossRef] [PubMed]

30. Gerlache, M.; Sentürk, Z.; Viré, J.C.; Kauffmann, J.M. Potentiometric analysis of ionic surfactants by a new type of ion-selective electrode. Anal. Chim. Acta 1997, 349, 59-65. [CrossRef]

31. Heinig, K.; Vogt, C. Determination of surfactants by capillary electrophoresis. Electrophoresis 1999, 20, 3311-3328. [CrossRef]

32. Kawase, J.; Nakae, A.; Yamanaka, M. Determination of anionic surfactants by flow injection analysis based on ion-pair extraction. Anal. Chem. 1979, 51, 1640-1643. [CrossRef]

33. Qian, J.; Qian, X.; Xu, Y. Selective and sensitive chromo- and fluorogenic dual detection of anionic surfactants in water based on a pair of "on-off-on" fluorescent sensors. Chem. Eur. J. 2009, 15, 319-323. [CrossRef] [PubMed]

34. Coll, C.; Casasus, R.; Aznar, E.; Marcos, M.D.; Martinezmanez, R.; Sancenon, F.; Soto, J.; Amoros, P. Nanoscopic hybrid systems with a polarity-controlled gate-like scaffolding for the colorimetric signalling of long-chain carboxylates. Chem. Commun. 2007, 1957-1959. [CrossRef]

35. Nakashima, H.; Yoshida, N. Fluorescent molecular sensing for various types of surfactants using amino- $\beta$-cyclodextrins bearing naphthalene chromophore. Chem. Lett. 2006, 35, 1168-1169. [CrossRef]

36. Stroud, J.L.; Paton, G.I.; Semple, K.T. Microbe-aliphatic hydrocarbon interactions in soil: Implications for biodegradation and bioremediation. J. Appl. Microbiol. 2007, 102, 1239-1253. [CrossRef] [PubMed]

37. Kumar, S.; Singh, P.; Mahajan, A.; Kumar, S. Aggregation induced emission enhancement in ionic self-assembled aggregates of benzimidazolium based cyclophane and sodium dodecylbenzenesulfonate. Org. Lett. 2013, 15, 3400-3403. [CrossRef] [PubMed] 
38. Hussain, S.; Malik, A.H.; Iyer, P.K. Highly precise detection, discrimination, and removal of anionic surfactants over the full ph range via cationic conjugated polymer: An efficient strategy to facilitate illicit-drug analysis. ACS Appl. Mater. Interfaces 2015, 7, 3189-3198. [CrossRef] [PubMed]

39. Chen, $X$. Colorimetric sensing of non-ionic and cationic surfactants using a versatile anionic poly(3,4-propylenedioxythiophene) derivative. Anal. Methods 2015, 7, 2800-2805. [CrossRef]

40. Meng, G.; Luochao, W.; Junjian, C.; Shiwu, L.; Guanhai, L.; Lin, W.; Yingjun, W.; Li, R.; Anjun, Q.; Zhong, T.B. Aggregation-induced emission active probe for light-up detection of anionic surfactants and wash-free bacterial imaging. Chem. A Eur. J. 2016, 22, 5107-5112.

41. Sandhu, S.; Kumar, R.; Tripathi, N.; Singh, H.; Singh, P.; Kumar, S. Lab-on-a-molecule elaboration for fluorescence based discrimination of commercial surfactants sodium dodecyl sulfate and sodium dodecylbenzenesulfonate. Sens. Actuators B Chem. 2017, 241, 8-18. [CrossRef]

42. De Borba, E.B.; Amaral, C.L.C.; Politi, M.J.; Villalobos, R.; Baptista, M.S. Photophysical and photochemical properties of pyranine/methyl viologen complexes in solution and in supramolecular aggregates: A switchable complex. Langmuir 2000, 16, 5900-5907. [CrossRef]

43. Biesalski, M.; Johannsmann, D.; Rühe, J. Electrolyte-induced collapse of a polyelectrolyte brush. J. Chem. Phys. 2004, 120, 8807-8814. [CrossRef] [PubMed]

44. An, Y.X.; Bai, H.; Li, C.; Shi, G.Q. Disassembly-driven colorimetric and fluorescent sensor for anionic surfactants in water based on a conjugated polyelectrolyte/dye complex. Soft Matter 2011, 7, 6873-6877. [CrossRef]

45. Li, C.; Numata, M.; Takeuchi, M.; Shinkai, S. A sensitive colorimetric and fluorescent probe based on a polythiophene derivative for the detection of atp. Angew. Chem. 2005, 44, 6371-6374. [CrossRef] [PubMed]

46. Miyake, M.; Kakizawa, Y. Study on the interaction between polyelectrolytes and oppositely charged ionic surfactants. Solubilized state of the complexes in the postprecipitation region. Colloid Polym. Sci. 2002, 280, 18-23. [CrossRef]

47. Kuhn, P.S.; Levin, Y.; Barbosa, M.C. Complex formation between polyelectrolytes and ionic surfactants. Chem. Phys. Lett. 1998, 298, 51-56. [CrossRef]

48. Von Ferber, C.; Lowen, H. Complexes of polyelectrolytes and oppositely charged ionic surfactants. J. Chem. Phys. 2003, 118, 10774-10779. [CrossRef]

49. Yao, Z.Y.; Li, Y.G.; Li, C.; Shi, G.Q. Disassembly of conjugated polyelectrolyte aggregates and their application for colorimetric detection of surfactants in water. Chem. Commun. 2010, 46, 8639-8641. [CrossRef] [PubMed]

50. Yao, Z.Y.; Bai, H.; Li, C.; Shi, G.Q. Analyte-induced aggregation of conjugated polyelectrolytes: Role of the charged moieties and its sensing application. Chem. Commun. 2010, 46, 5094-5096. [CrossRef] [PubMed]

51. Zhang, X.-H.; Zhao, C.-F.; Li, Y.; Liu, X.-M.; Yu, A.; Ruan, W.-J.; Bu, X.-H. Two hexaazatriphenylene based selective off-on fluorescent chemsensors for cadmium(ii). Talanta 2014, 119, 632-638. [CrossRef] [PubMed]

(C) 2018 by the authors. Licensee MDPI, Basel, Switzerland. This article is an open access article distributed under the terms and conditions of the Creative Commons Attribution (CC BY) license (http://creativecommons.org/licenses/by/4.0/). 